\title{
Urban characterisation; Expanding applications for, and new approaches to building attribute data capture.
}

\author{
Polly Hudson ${ }^{\text {a* }}$ \\ ${ }^{a}$ The Centre for Advanced Spatial Analysis, UCL, London, UK; \\ *p.a.hudson@ucl.ac.uk
}

Polly Hudson is an EPSRC funded $\mathrm{PhD}$ student researching into spatial patterns of demolition at the Bartlett Centre for Advanced Spatial Analysis, University College London. She trained as an architectural historian and has worked in historic building site management, and museum and exhibition design, setting up The Building Exploratory charitable trust in 1995. Over the past twenty years she has designed many GIS related projects. Since 2004 her work has focused on visualising and analysing rates of change in cities, in the context of energy and urban resource conservation. She was awarded a visiting fellowship at The Centre for the Historic Environment, Kellogg College, University of Oxford in 2010 and was an Honorary Research Associate at CASA between 2014 and 2016. She has also held public appointments with English Heritage, the Department of Culture, Media and Sport, The National Lottery (charitable arm) and the Royal Institute of British Architects. 


\section{Urban characterisation; Expanding applications for, and new approaches to building attribute data capture.}

As cities face increasing pressure to develop effective long-term sustainability strategies, the need for detailed quantitative data on urban resources, and their behaviour over time, becomes ever more critical. Building stocks are a city's largest socio-cultural and economic resource and account for around $40 \%$ of total energy consumption in developed countries. Despite ongoing problems with access to data on stock composition and dynamics, advances are now being made particularly within sustainability. Automated approaches to the analysis of historical building attribute data are also allowing long-term patterns of change in cities to be better understood. This is of significance to the conservation sector, and the development of effective conservation strategies. At the same time knowledge held by the conservation sector is of growing importance to sustainability science. This paper selects specific advances within this new research landscape, and identifies their importance in developing a more scientific, data driven approach to the analysis of older stock. It concludes with an introduction to a new type of data collection and visualisation platform being developed for London, as a result of this review.

Keywords: energy, urban rules, sustainability, urban science, building stock, building attribute data, VGI, machine learning, knowledge transfer, HUL

Subject classification codes: include these here if the journal requires them

This work was supported by the Engineering and Physical Science Research Council, under a CASA studentship. Award number 1495762. 


\section{Introduction}

As cities face increasing pressure to conserve urban resources and reduce emissions, the need to measure these resources, their impact, value and potential for reuse, becomes ever more critical. How much/many do we have? Where are they located and why? How old are they and how might their lifespans be extended? At what rate are they currently being depleted and what is likely to be the socio-cultural, economic and environmental impact of their loss in both the short and longer term? These questions have, until recently, rarely been asked about the building stock as a whole; despite it being considered the largest physical, economic and cultural capital of a society (Bradley \& Kohler, 2007: 530). However, a far greater understanding of the long-term behaviour, and contribution, of stocks and their buildings and building typologies is required if the role of older stock in supporting sustainable, vibrant cities is to be better understood.

The socio-cultural and economic value of historic buildings is widely recognised in many advanced economies today (UNESCO, 2017). Attention on older buildings has, in large part, focused on those protected by designation, which constitutes around $1-2 \%$ of European stocks (Kohler \& Hassler, 2002). The role of non-designated older buildings, in contributing towards successful and sustainable cities, is less well studied.

In 1961 Jane Jacobs made her, now well-known call for older buildings to be recognised as a critical component in successful cities.

'Cities need old buildings so badly it is probably impossible for vigorous streets and districts to grow without them. By old buildings I mean not museum-piece old buildings, not old buildings in an excellent state of rehabilitation- although these make fine ingredients- but also a good lot of plain, ordinary low-value buildings, including some run down old buildings' (Jacobs, 1961: 187). 
Jacobs argued that older districts, owing to their incremental development over time, often contained buildings of diverse age, size and form, which in turn generated a range of rental values. Such a range, she argued, was necessary to attract the diverse building uses, and their user populations, required to stimulate innovation, and to generate social and economic vitality within cities. (Jacobs, 1961).

Jacobs' theories can be seen reflected in the 2011 UNESCO 'Recommendation on the Historic Urban Landscape' (HUL) which describes both tangible and intangible urban heritage as 'sources of social cohesion, factors of diversity and drivers of creativity, innovation and urban regeneration' (UNESCO, 2017: 5). The 2011 Recommendation also advocates a more comprehensive approach to the urban landscape whereby designation overcomes notions of 'monument' to understand the historic value of cities as the collective result of dynamic urban processes. The approach addresses the extended built fabric in its natural and manmade context and calls for a set of tools that will enable informed policy making and planning. Towards the development of such tools, the role of comprehensive building survey data is of core significance and relates to various levels of the HUL characterisation: from knowledge and planning for socio-economic and environmental sustainability, to civic engagement and community-led urbanism.

The capture of digitised survey data relating to the character and evolution of the historic landscape, using Geographic Information Systems (GIS), was spearheaded by the conservation sector in the 1990s. Until recently the exploitation of these large-scale geographic surveys has remained limited. However, the growth of energy legislation along with technological advances in computing, spatial analysis and rule-based machine learning, and the open data movement are now resulting in a rapid redefining of this field.

This paper provides an opportunity to bring together recent research into the collection 
and application of spatial data relating to the physical character, and age, and evolution of the building stock, from a number of fields. We show how these data are enabling new, rapidly gained, insights into the contribution and behaviour of older urban stocks as a whole, in a way never possible before. We flag the relevance of these advances for the urban heritage sector in supporting more effective policymaking relating to the sustainable management of cities. We also highlight the critical importance of engaging the conservation sector in both the identification and verification of data owing to its unparalleled body of knowledge. Furthermore, we believe the sector has a crucial role to play in working with urban scientists in the identification of long-term patterns of behaviour within stocks to aid more effective and sustainable policy making.

\subsection{Applications}

\subsection{Measuring socio-economic value in older stock}

The HUL Recommendations identify urban heritage as an economic, as well as a social and cultural asset, defined by a successive layering of values which in turn generate uniqueness and diversity. (UNESCO, 2011: 1). In the past decade an increasing number of studies have forwarded the economic case for the retention of older stock (Hassler, 2009; HLF, 2013; Power \& Katz, 2016; Licciardi \& Amirtahmasebi, 2012), as posited by Jacobs in the 1960s (Jacobs, 1961).

However, until recently lack of adequate statistical data on urban building stocks as a whole has impeded large-scale quantitative studies into the contribution of older stock to the economic vitality of cities. In 2014 a ground-breaking report entitled 'Older, Smaller, Better' was published by the National Trust for Historic Preservation's Green Preservation Lab in the US (NTHP, 2014). Developed with a multidisciplinary team, including conservation and urban specialists, data scientists, and economists, the study 
set out to validate Jacob's theories regarding the socio-economic value of older buildings, and age diversity within the stock. It was made possible only through the open release, by a number of US cities, of citywide spatial building attribute data used for property tax evaluation, discussed further in Section 3.2 The report also noted that. 'Data on the historic built environment is generally difficult to locate and often exists only in nondigital files.' (NTHP, 2014: 21). This important new data source is discussed further in section 3.2.

Using a grid of 200x200m squares spread across the urban landscape of three US cities, Seattle, San Francisco and Washington DC, statistical analysis was undertaken to assess the 'character' of buildings within mixed use and commercial areas, using their building size, age and age diversity. 'Character' ratings were then correlated against forty economic, social, and environmental performance metrics, with areas with high character ratings found to be more likely to house small start-ups, be more inclusive in cultural makeup and create more jobs per square foot than areas with larger buildings of similar age. The research, which focused on ways of stimulating sustainable economies and strengthening local communities, also identified the relevance of the methodology to the evaluation of many types of urban programme, ranging from health and urban regeneration, to tax credit implementation. In addition, evidence was also gathered (using only data on the extant stock) on the impact of long term dynamic behaviour: 'The higher performance of areas containing small-scale buildings of mixed vintage suggests that successful districts evolve over time' (NTHP, 2014: 12). 


\subsection{Energy analysis and monitoring; urban metabolism and building survival rates}

The most significant recent advances in our understanding of the composition and behaviour of urban stocks as a whole, and of older buildings within them, have been driven by the energy sector. Buildings account for $40 \%$ of total energy consumption in developed countries (Tooke, et al., 2013), with a third of consumption attributed to the built environment in global terms (IEA, 2013). By 2050 it is estimated that urban building stocks will contain $66 \%$ of the world's population (United Nations, 2014), with around $80 \%$ of Europe's 500 million inhabitants already living in cities and towns (Power \& Katz, 2016). In 2011 the European Commission's Energy Efficiency Plan identified buildings as resources where 'the greatest energy saving potential lies' (European Commission, 2011: 3).

Since the 1990s growth in energy legislation has led to a paradigm shift within the European construction industry from new build to refurbishment; given impetus by the 2008 EU Waste directive which prioritised the adaptive reuse of buildings over the recycling of materials (Huuhka \& Lahdensivu, 2016). With this shift, a stock focused view has come to replace what Kohler, Steadman and Hassler describe as: 'the fascination for continuous growth in input flows, and the ignorance of output flows and side-effects. There is an increasing recognition of the need to understand the characteristics and dynamics of national building stocks at different levels' (Kohler, et al., 2009: 449). The size of the stock, its poor energy performance compared to other resources and its relatively slow rate of change, with new construction comprising annually on average $1 \%$ of European stocks (Hassler, 2009), and demolition 0.05 to $0.3 \%$ (Thomsen \& Flier, 2011), has meant that the most significant challenge in exploiting this energy saving potential is the systematic renovation of older stock (BPIE, 2011). 
Problems with an ongoing focus on new build and the need to address adaptation and renewal in mature settlements were already being raised within the conservation sector in the 1990s (Larkham, 1996). Today it is increasingly recognised that sustainable planning, energy reduction and the conservation of existing resources, identified within the HUL Recommendations, will to a large extent rely on the refurbishment of existing older stock. This focus on refurbishment and reuse is now leading to basic principles of building conservation, such as incremental change, reuse and maintenance, and extension of building lifespans, beginning in many countries to be promoted as mainstream energy related objectives. Research by Hassler and Kohler (Hassler, 1996; Kohler \& Hassler, 2002) provides detailed insights into the interlinking of these common goals.

Focus on refurbishment has also meant an increased interest in the makeup and future behaviour of existing stocks and an urgent need for more information about them. Energy analysis of the building stock is now a highly active research field, with the Energy Performance of Buildings Directive 2010 (EU, 2010) being a significant policy driver (BPIE, 2011). Detailed building attribute datasets at city and country scale are now relevant to, and sought after, for emission calculations, emissions regulation and the modelling of low emission building design. Land use, size and more recently age, are key data types for these applications. Age is now recognised as an important indicator of building materials, structural systems, morphology and geometries ( Aksözen, et al., 2015; Neidhart \& Sester, 2004; Schiller, 2007; Tooke, et al., 2013). These data are also required for modelling design interventions across building stocks to reduce heating and cooling, (Symonds, et al., 2017), the most important factor in building related energy consumption (Salvati, et al., 2017; Symonds, et al., 2017). The more accurate and fine grained attribute data are, the more useful they will be in these areas of research.

A growth area of research now relates to building lifecycles and lifecycle assessments 
(LCAs). Evidence, produced within Sustainability Science, has demonstrated that most buildings are not destroyed as a result of material ageing (Abramson, 2016; Kohler \& Hassler, 2002; O’Connor, 2004; Thomsen \& Flier, 2011); though building lifespan will be affected by initial design and construction quality, and regularity and ease of maintenance. Construction industry methods of estimating lifespan are now acknowledged to result in theoretical constructs (Hassler, 2009), with Liu et al arguing that lifespans are underestimated in Europe and overestimated in China where standards prescribe a service life of 50 years but lifespan is closer to 30 years (Liu, et al., 2014). Accurate building lifespan estimates are extremely important as small differences in projected survival will make a considerable difference to energy and carbon calculations and the costs of life extension over demolition (O’Connor, 2004).

Lifespan calculations are now being used in studies relating to the 'metabolism' of cities; that is the speed, scale and extent of construction and demolition over time, and consequent material and energy flows. These are linked to the relatively new science of Industrial Ecology which looks at increasing eco efficiency in cities and other industrial systems through 'closing material flows into loops of recycling and reuse' (Hond, 2000: 61). Methods of extending building lifespans are seen as an essential way of reducing flows: 'a sustainable society should minimize its environmental impact by reducing extraction of those resources. To minimize extraction, existing stocked material should be used for as long as possible'. (Tanikawa \& Hashimoto, 2009: 484). This has led in turn to the question of the 'optimal speed of transformation' of stocks over time (Aksözen et al., 2017: 256), with Kohler and Yang also arguing that one of the most significant issues relating to the long term behaviour and sustainability of cities and their building stocks is their rate of change (Jacobs, 1961; Kohler \& Yang, 2007).

Large-scale studies analysing building survival rates have been carried out over the past 
decade in Ettlingen, Germany (Bradley \& Kohler, 2007), Zurich, Switzerland (Aksözen, et al., 2017), Wakayama, Japan, and Salford in the UK (Tanikawa \& Hashimoto, 2009). These track the demolition and construction of stocks over extensive time periods, drawing from archive data ranging from statistical records to historical maps and archive images.

In Aksözen et al.'s recent analysis of Zurich's stock (Aksözen, et al., 2017) the following questions were posed: 'How many buildings have existed in this stock since its origin?', 'How long do buildings last?' and 'Why are buildings demolished?' To address these questions the stock was meticulously 'reconstituted' by identifying construction and demolition dates for all buildings built over a 224-year time frame, including those that had been lost. Statistical data were derived, for the current stock and recent demolitions, from Statistik Stadt Zürich, with information on historical demolitions accessed via Statistisches Jahrbuch der Stadt (which provided a statistical yearbook from 1905). These combined with additional sources were then used to estimate missing data (Aksözen, et al., 2016) and find answers to the questions posed.

Tanikawa and Hashimoto's 2009 research into material stock flows in Wagayama and Salford focused more on the spatial redistribution of materials, and the calculation of material waste. Their study covered a 150 year timespan and also included generated survival estimates, along with demolition curves for specific types of buildings. Vectorised historical topographic maps, aerial images and archive photos were here employed within a 4D GIS system (Tanikawa \& Hashimoto, 2009). A detailed summary of a range of top down and bottom up approaches to data analysis in the context of industrial ecology can be found in Tanikawa et al.'s paper 'The weight of society over time and space' (Tanikawa, et al., 2015). Figure 1 provides examples of material stock flow illustrations produced for Nagoya, Japan, illustrating the use of building survey data 
to identify the changing spatial distribution of construction materials between 1970 and 2009.

\subsection{Urban science: Codes, rules and predictive analysis}

Interest in detailed building attribute data, for both current and historical city stocks, has also come from the field of urban science. Here data are of particular value in underlying rules determining the ways the physical fabric of cities operate and behave over time. Though Batty noted in 2007 that 'the notion of temporal dynamics [in urban science] is almost entirely absent' (Batty, 2007: 2-3), interest in historical data in urban science has grown in the last decade, largely advanced by Batty himself. His work is of particular relevance in its re-examination of Jacob's, and of Christopher Alexander's work; its advancement of research into, and its recognition of the value of long time series data in predictive spatial models.

Batty argues that between the mid twentieth century and the early twenty first century the concept of cities as machines moved to one of cities as organisms (a view reflected in Industrial Ecology and discussed by Jacobs and Alexander). In parallel, has come a shift in interest from top-down to bottom-up planning, from design structures to emerging forms, and from concern with form to concern with process (Batty, 2006). Since the 1990s a new breed of urban computer models has emerged. More physical in form these models focus on land use and land use change, employing rule-based, machine learning algorithms to simulate urban interactions, and in doing so generate large-scale patterns able to aid the understanding and managing of the complexity of cities (Batty, 2007). 'Complex systems are path dependent...thus 'history matters' and systems are said to 'lock in' to a process or pattern' (Batty, 2006). Jane Jacobs was in fact the first person to apply Warren Weaver's theory of organised complexity to the city (Batty, 2007); arguing 
that urban problems could not be unravelled from a purely top-down perspective but required an understanding of long term processes, bottom-up interactions, a 'microscopic' view across cities and grass roots knowledge (Jacobs, 1961).

With this approach has come an awareness, within urban science, of the limited availability of granular data relating to the urban fabric and of spatiotemporal data: 'So far most of this science has been a timeless science... Cities look like they are in equilibrium physically because of the inertia of the built environment, temporal data is inordinately hard to get' (Batty, 2013: 34). Between 2005 and 2010 large-scale spatiotemporal datasets for London were generated for use in a range of computational studies overseen by Batty. Historical street networks were manually vectorised for nine timeslices between 1786 and 2010. These were then analysed to determine patterns of growth, with a particular interest in scaling laws that demonstrate consistent behaviour over time and space (Batty, et al., 2014; Masucci, et al., 2014, 2013; Murcio, et al., 2015).

As part of the study a high resolution longitudinal land use database was created by Kiril Stanilov. This traced patterns of land development in a $200 \mathrm{~km}^{2}$ area of West London between 1875 and 2005 (Stanilov, 2012; Stanilov \& Batty, 2011). Sixty types of land use were digitally traced from maps from seven Ordnance Survey historical surveys to produce vectorised data that could be analysed and interrogated. Changes in patterns of use from one survey to the next were analysed in relation to distance from the central business district, major roads, railway and underground stations and suburban centres. Specific policies relating to, for example, new densities and green belt constraints were also assessed along with scholarly works on the history and planning of the city. Drawing from this research and from spatial patterns identified between each of the first three surveys $(1875,1895,1915)$, rules, relating to the way land use changed over time, were then created. These were fed into a cellular automaton model in which the land area was 
subdivided into cells on the grid. The cells changed their state/ land use through discrete time steps according to the rules determined by the analysis. Rules were then iterated to produce computer generated predictions for 1935, 1960, 1985 and 2005 which could then be verified against actual map survey data.

The remarkable level of accuracy of this method can be seen in Figure 2. Through analysis of these data Stanilov and Batty were also able to provide evidence that planning played an important role in shaping the patterns of urban expansion within London, but that how it expanded was also strongly influenced by the pre-urban spatial structure and a set of consistent rules or 'urban code', able to describe the way in which land uses interact spatially with elements of the built environment across time and space. (Stanilov, 2012).

\subsection{Data}

\subsection{Data accessibility}

Difficulties in accessing large-scale building attribute datasets, able to support analysis into the dynamics of the building stock, were already highlighted by the energy sector in the 1990s, (Moffat, 1997 quoted in Kohler \& Hassler, 2002) with studies seen to be 'seriously limited by the absence of reliable statistical data, international research confirm this lack world-wide' (Kohler \& Hassler, 2002: 231-32).

In 2007 the INSPIRE directive came into force designed to create a European spatial data infrastructure, to facilitate cross-border working, data sharing and standardisation (INSPIRE, 2017). However, in 2011 the lack of attribute data was still being highlighted by the Buildings Performance Institute of Europe in 'Buildings under the Microscope', its ambitious study into the makeup of the European stock and into energy monitoring and regulation. The report concluded that data were needed, urgently, to monitor and 
evaluating energy policies (BPIE, 2011: 25), with information on building age, size and use being key data categories required. In 2013 Canadian researchers were also flagging the problem in identifying baseline energy conditions owing to challenges in accessing data. (Tooke, et al., 2013).

Incompleteness, fragmentation, aggregation and inconsistency and/or restrictions relating to non-spatial and spatial statistics for building characteristics, demolitions, and lifespans have now been raised in many energy related studies (Kohler \& Hassler, 2002; Aksözen, et al., 2015; Huuhka \& Lahdensivu, 2016; Liu, et al., 2014; Miatto, et al., 2017; Ravetz, 2008; Steadman, et al., 2014; Tanikawa \& Hashimoto, 2009; Thomsen \& Flier, 2011; Tooke, et al., 2014). Factors influencing the partial view of the characteristics of urban stocks, and the wide difference in knowledge and access to these data within different countries include: different sectors' historical foci on single stock areas with limited objectives; prioritisation of residential over non- residential stock for example; focus public housing owing to state investment; construction industry interest in new build and technological innovation, and the conservation sector's specific remit with regard to designated assets (Kohler \& Hassler, 2002). This has resulted in a lack of consistency in the capture of building attributes other than, as we shall see, for property tax and land ownership purposes.

\subsection{Property tax databases and data visualisations}

\subsubsection{Release}

Property databases developed for taxation or land registration purposes appear to form the most comprehensive databases available on the current composition of national building stocks. In the case of property tax valuations detailed information on the characteristics of each property (for example size, age and use) is required for all taxable 
properties in a country (United Nations, 2013). Accurate and updated data are important to minimise potential challenges to valuations, as it is on these that valuations are based. As previously noted property tax data has also been shown to be of value to economic analysis.

However, access to these data varies considerably. In the UK, for example, large-scale property tax data at premises level are restricted by government even to academia (VOA, 2017), contrasting with the Netherlands where such information is freely available (BAG 2017; Spaan, 2015). In North America many city authorities since 2013 have uploaded and released previously charged for property tax datasets into the public domain (Open data.stack exchange, 2015; OKFN, 2017). This has occurred as part of the 'big data' movement in which large-scale datasets are released to explore patterns and trends, and enable 'more efficient, sustainable, competitive, productive, open and transparent cities' (Kitchin, 2014: 1).

\subsubsection{Colour visualisation}

Property attribute data release by governments has also resulted in a global trend for city age visualisations (Mason, 2013; NYC, 2017; Spaan, 2015), triggered in 2013 by Justin Palmer's visualisation of age data for Portland Oregon (Palmer, 2017). In Figure 3 we see an extract from Bert Spaan's visualisation of the age of over nine million buildings in the Netherlands using the BAG building registration data (BAG, 2017). These visualisations raise a number of points: firstly that a vast body of free technical expertise exists online available to visualise and analyse published attribute data; secondly that, as seen in the NHTP study, urban problem solving and innovative approaches are more likely to occur in countries and cities where high quality large-scale building attribute databases have been released; thirdly that methods of verifying and updating data on an ongoing basis 
are essential, and fourthly, based on public reaction, that significant public interest in the visualisation of spatiotemporal data is also likely to exist.

The value of collecting and visualising comprehensive data for cities as a whole at building level, in colour, was already recognised at the beginning of the twentieth century. In 1916 Hugo Hassinger 'Historical Atlas of Vienna' was published. Hassinger was one of the first scientists to use colour in the mapping of physical forms (Whitehand, 2007), even differentiating in some cases between facades and building cores (Clarke \& Simms, 2015: 15). His work formed part of the emerging field of urban morphology and, within it, the study of morphogenetics and the tracing of the historical evolution of urban form (Whitehand, 2007). His application of the power of cartographic visualisation to justify German appropriation of land in the Second World War (Herb, 2002) possibly explains the lack of wider adoption of colour coded age mapping after the war. The mapping of land use and building storeys (recorded though depth of colour, by Walter Geisler in Gdansk in 1918 is also worthy of note. This was to influence M.R.G Conzen, who in 1918 also mapped building height for a number of German towns (Whitehand, 2007) and went on to spearhead urban morphology in Britain and the characterisation of its urban landscapes.

\subsubsection{Verification and updating}

The international trend for age data visualisation has also facilitated greater scrutiny of age data, opening up opportunities for specialists and residents to comment on, and in some cases correct, inaccuracies and omissions. In 2012 data errors were quickly noticed by Columbia University's Historic Preservation Unit when building age data for New York City, derived from the PLUTO property tax database was visualised online (Brooklyn 11211, 2013). The visualisation website produced by Brandon Liu (Liu, n.d.) 
now highlights potential errors and directs users to a range of sources against which individual buildings may be checked.

New methods of updating property tax databases are also being tested. In the Netherlands, Volunteered Geographic Information Systems (VGI) are being used to encourage residents to correct and update data themselves. This allows for continuous updating (rather than four year intervals) with valuation appeals found to reduce, quality of data to improve, and missing data to often be voluntarily included by owners (Reimerink, 2016). In Anne Arundel County in the US a different approach is taken whereby aerial photography is assessed alongside existing property tax data (Anne Arundel County, 2017). This method was also found to accelerate property tax reviews, and to minimise review costs and increase tax revenues through the identification of undocumented property (Peccarelli, 2017). Verification and updating of urban attribute datasets, particularly in with regard to information on building age and site rebuild history, is seen here as a vital future role for the urban conservation sector.

\subsection{Automated building attribute generation}

Increased demand for citywide building attribute data within energy analysis now runs parallel to widely differing access to comprehensive datasets for countries and cities, with a 2013 study noting that in Canada property tax age data was expensive and unavailable for specific locations (Tooke, et al., 2013). This has led to the development of new approaches to the automated capture and extraction of building attribute data from remotely sensed data and from topographical maps, and its classification using knowledge-based approaches or data-driven learning techniques (e.g. Hecht, et al., 2013). This is now enabling low cost, building attribute data generation, to begin to be generated, rapidly, for large geographic areas. 


\subsubsection{LiDAR}

Automated classification of land use from remote sensing data (such as aerial photography and satellite imagery) was tested from the 1980s. Early studies by Barnsley and Barr demonstrated that land classes could be determined based on morphological qualities and spatial relations, with a number of studies undertaken in this area since 2003 (Hecht, et al., 2013).

LiDAR (otherwise known as light detection and ranging) is an active remote sensing technique based on an echo-return principle. Sensors attached to aircraft capture information by sending pulses of light to the ground, and measuring time of travel to and from a building, in relation to aircraft position (Azman, et al., 2015). LiDAR is relatively low cost, has high rates of capture of around $100 \mathrm{~km}^{2}$ per hour, high accuracy and precision (with up to a million data points per $\mathrm{km}^{2}$ ) with data able to be captured regardless of terrain or weather (Lemmens, 2007). It is used to produce detailed digital surface models (DSM) formed through 3D 'clouds' of data points 3D urban models visualised in Figure 4 (see also Roumpani, 2016).

The generation of 3D buildings, from which detailed roof topologies could be also derived, was already being tested in Germany in 2000 (Neidhart \& Sester, 2004). In 2004 Neidhart and Sester used building volume data generated from LiDAR, along with building footprints extracted from topographical GIS maps and road network data to test the use of LiDAR in increasing accuracy in the measurement of heat demands across large geographic areas. The characteristics of existing dwelling typologies were then used to create rules to allow the computer to recognise specific building types. The typology

\footnotetext{
'describes the characteristics of the buildings on a level which is made for human interpretation. Therefore, the main task is to set up rules that can infer the building type from a set of observable and measurable building characteristics, and thus link
} 
the mere geometric data with specific heat coefficients' (Neidhart \& Sester, 2004:

2).

Rules were generated in relation to building size, roof type and distance to neighbouring buildings and roads. Computers were then 'trained' using pre-classified 'training data' to automatically recognise and classify building footprints according to these rules. Heat demand was then calculated using the newly classified data.

In 2013 Tooke et al. built on the potential of Lidar 'to generate detailed information related to building geometry and design' to see whether improvements could be made not only in the prediction of energy performance but also in the prediction of building age. The study, which also explored potential links between age, design and geometry, concluded that building age data could be estimated relatively accurately in this way, and that height data was the most important attribute data in its prediction (Tooke, et al., 2013: $603)$.

\subsection{Topographical maps and historical attribute data}

Advances in automated data capture and classification from historical mapping now offer new possibilities for the dynamic modelling of buildings stocks, through their rapid generation of high quality, low cost and large-scale datasets. Time series data also allow for insights to be gained into the persistence of building typologies and configurations over large spatiotemporal frameworks, facilitating new existing investigations into adaptable and resilient urban forms.

In Germany, research is being undertaken into the automated data extraction and classification of buildings using vectorised building footprints derived from contemporary and historical topographical maps (Hecht, et al., 2013; Herold, 2015; Meinel, et al., 2009). This approach is likely to open up the way in which historical spatial 
data relating to cities' stocks are used. It is also already pushing forward research into resilient building configurations and forms, complementing detailed studies undertaken within urban morphology, historic building research and the science of form.

In 2013 Hecht et al. published a comparison of data sources (satellite imagery, aerial photography, Lidar, cadastral data, digital landscape models and topographic maps) from which urban structures could be derived (Hecht, et al., 2013). The research concluded 1:25,000 maps were the most suitable for building attribute extraction, being widely available, low cost, having extensive geographic coverage and, crucially, being available for a range of historical timepoints (ibid.). Timeseries data are particularly relevant to the analysis of building lifecycles and urban metabolism studies which 'require enormous amounts of data which are difficult to collect'. (Hond, 2000: 64). As Satori et al. also note: 'Long-time series are needed when modelling systems with long lifetimes' (Sartori, et al., 2016: 16).

In Hecht at al.'s study, Figure 5, topographical maps were first scanned and building footprints automatically extracted using pattern recognition software (Hecht, et al. 2013). As in Neidhart and Sester's work a series of building types were identified derived from specialist knowledge of the building stock. 'Training data' were then used to enable computer classifiers to recognise each building type. Data were then aggregated, with the dominant type determining the urban structure at block level. Though a high level of accuracy was found against the reference data overall, accurate recognition of certain typologies was identified as needing further research.

As we have seen, the automated vectorisation of building footprints forms a crucial step in enabling spatiotemporal attribute data to be made available at large geographic scales. A growing number of archives and libraries are now also assisting this process through 
the scanning, georeferencing and or/ release of their historical maps (British Library, 2017; NLS, 2017; NYPL, 2017a). Volunteered Geographic Information (VGI) projects are also being used to accelerate georeferencing programmes (British Library, 2017), with The New York Public Library's 'map warper' now complemented with a manual building vectorisation tool (NYPL, 2017b).

\subsection{Summary/Creating knowledge interfaces}

The HUL recommendations identify the need for, both, civic engagement tools able to involve and empower diverse stakeholders and facilitate dialogue, and, knowledge planning tools which, amongst other roles, support the mapping and monitoring of urban heritage. The growing number of applications for spatiotemporal data is now demanding an increase in automated approaches for the capture, classification and dissemination. This will facilitate their use in analysis and prediction enabling more effective conservation and sustainability policies for cities to be developed. However, to increase data availability, and to improve accuracy and quality of data (and accuracy of analysis with regard to time series data) the vast body of knowledge held within the urban conservation sector needs now to be harnessed.

In response to this challenge; to the paucity of attribute data available on London's buildings and to the growing demand from UK energy researchers for detailed and comprehensive building attribute data, a new type of civic engagement and knowledge planning tool is currently being tested in London. Designed by the author, in collaboration with colleagues at The Bartlett Centre for Advanced Spatial Analysis, UCL, 'Colouring London' (http://colouringlondon.org/) is a Volunteered Geographic Information (VGI) initiative. Launching in 2019 it will provide online platform that captures, collates and visualises quantitative spatiotemporal building attribute data relating to London's current 
and past stock. The project is being developed with the UK's national mapping agency, Ordnance Survey, The Greater London Authority and Historic England, and aims to become to the first port of call for data on London's buildings. Target data users include those working in energy analysis, planning, construction, sustainable management and conservation as well as residents, visitors and schools.

The project builds on widespread interest in city age visualisations, the success of VGI projects such as Wikipedia, and the growth in citizen science platforms (Hacklay, 2012: 105-122) such as Galaxy Zoo and Penguin Watch. Twelve categories of data will be collected, including building age, as shown in Figure 6, land use, building type, size, conservation status, and rebuild history. The platform will also experiment with methods of increasing answerability in planning by, for example, allowing all buildings by specific developers and architects to be tracked, and enabling users to click on a 'like me' option (with each 'like' deepening the building's colour). Demolition history will also be tracked to support investigations into resource loss and energy related flows. Information gathered on specific typologies and ages will also be able to be correlated, as in the NTHP study, with socio economic and environmental data.

Research also is being undertaken, funded by Historic England, into the integration of historic building records, and the engagement of the historic buildings sector in the project's development. The aim is also to use the project to reposition the UK's historic building sector at the heart of new data-driven urban research, and to increase the amount of research undertaken within urban science which uses construction age and time series data to unpick 'urban codes' and repetitive patterns of change within the urban landscape. This is considered to be essential if we are to maximise efficiency in the stock, minimise emissions, exploit the potential of our finite building reserves, and more carefully calibrate rates of change within cities to provide for a more sustainable future. 
References

Abramson, D. 2016. Obsolescence. Chicago: Chicago Press.

Aksözen, M., Daniel, M., Hassler, U. \& Kohler, N. 2015. Building Age as an Indicator for Energy Consumption. Energy and Buildings 87(January): 74-86.

Aksözen, M., Hassler, U., Rivallain, M. \& and Kohler, N. 2016. Mortality Analysis of an Urban Building Stock. Supplementary Information. Building Research \& Information 45(3): 259-77. Video. Published online: 31 Mar 2016

Aksözen, M., Hassler, U., Rivallain, M. \& and Kohler, N. 2017. Mortality Analysis of an Urban Building Stock. Building Research \& Information 45(3): 259-77.

Anne Arundel County. 2017. County Maps \& GIS Data | Anne Arundel County, MD. [online] [accessed 14 November 2017]. Available at: <http://www.aacounty.org/county-maps/>.

Azman, B., Bull, G. \& Amirah, N. 2015. “A Brief History of LiDAR.” Earth Science.

BAG. 2017. Basisregistraties Adressen En Gebouwen. [online] [accessed 14 November 2017]. Available at: <https://www.kadaster.nl/wat-is-de-bag>.

Batty, M. 2006. Complexity, Prediction and Planning. In AESOP 3rd Meeting of the Thematic Group on Complexity. Cardiff.

Batty, M. 2007. Cities and Complexity. Cambridge: MIT Press.

Batty, M. 2013. A Science of Cities. Santa Fe Institute. [online] [accessed 14 November 2017]. Available at: <http://www.spatialcomplexity.info/files/2013/04/BATTYA-Science-of-Cities-SANTA-FE-2013.pdf>.

Batty, M., Morphet, R., Masucci, P. \& Stanilov, K. 2014. Entropy, Complexity, and Spatial Information. Journal of Geographical Systems 16(4): 363-85.

BPIE. 2011. Europe's Buildings under the Microscope. BPIE - Buildings Performance Institute Europe. [online] [accessed 14 November 2017]. Available at: < http://bpie.eu/publication/europes-buildings-under-the-microscope/>.

Bradley, P \& Kohler, N. 2007. Methodology for the Survival Analysis of Urban Building Stocks. Building Research \& Information 35(5): 529-42.

British Library. 2017. Georeferencing. The British Library. [online] [accessed 14 November 2017]. Available at: 〈https://www.bl.uk/projects/georeferencing>. Clarke, H. \& Simms, A. eds. 2015. Lords and Towns in Medieval Europe: Maps and Texts. Abingdon: Routledge. 
European Commission. 2011. EU Energy Efficiency Plan 2011. [online] [accessed 14 November 2017]. Available at: < https://ec.europa.eu/clima/sites/clima/files/strategies/2050/docs/efficiency_plan_ en.pdf >.

Hacklay, M. 2012. Citizen Science and Volunteered Geographic Information: Overview and Typology of Participation. In: D. Sui, S. Elwood, M. Goodchild, eds. Citizen Science and Volunteered Geographic Information: Overview and Typology of Participation. Netherlands: Springer Netherlands, pp. 105-122.

Hassler, U. 1996. Space-Time Risks and the Ideal of Long-Term Stability. Cultural Heritage - Insights from Environmental Economics. Environment Department of the World Bank (June). [online] [accessed 14 November 2017]. Available at: Hassler - Heritage at Risk <journals.ub.uni-heidelberg.de>

Hassler, U. 2009. Long-Term Building Stock Survival and Intergenerational Management: The Role of Institutional Regimes. Building Research \& Information 37(5-6): 552-68.

Hecht, R., Hendrik H., Gotthard Meinel., G. \& Buchroithner, M. 2013. Automatic Derivation of Urban Structure Types from Topographic Maps by Means of Image Analysis and Machine Learning. ICC_proceedings 2013. [online] [accessed 14 November 2017]. Available at:@inproceedings\{Hecht2013AutomaticDO.

Herb, G.H. 2002. Under the Map of Germany: Nationalism and Propaganda 1918 1945. London: Routledge.

Herold, H. 2015. An Evolutionary Approach to Adaptive Image Analysis for Retrieving and Long-Term Monitoring Historical Land Use from Spatiotemporally Heterogeneous Map Sources. Dresden: Technishe Universitat Dresden.

HLF. 2013. New Ideas Need Old Buildings | Heritage Lottery Fund. [online] [accessed 14 November 2017]. Available at: < https://www.hlf.org.uk/new-ideas-need-oldbuildings>.

Hond, F. den. 2000. Industrial Ecology: A Review. Regional Environmental Change 1(2): 60-69.

Huuhka, S. \& Lahdensivu, J. 2016. Statistical and Geographical Study on Demolished Buildings. Building Research \& Information 44 (1): 73-96.

IEA. 2013. Transition to Sustainable Buildings. Strategies and Opportunities to 2050. International Energy Agency. [online] [accessed 14 November 2017]. Available 
at:

<https://www.iea.org/publications/freepublications/publication/Building2013_fr ee.pdf

INSPIRE. 2017. About INSPIRE | INSPIRE. [online] [accessed 14 November 2017]. Available at: <https://inspire.ec.europa.eu/about-inspire/563>.

Jacobs, J. 1961. Death and Life of Great American Cities, 1992 ed. New York: Vintage Books.

Kitchin, R. 2014. The Real-Time City? Big Data and Smart Urbanism. GeoJournal 79(1): $1-14$.

Kohler, N. \& Hassler, U. 2002. The Building Stock as a Research Object. Building Research \& Information 30(4): 226-36.

Kohler, N. \& Yang, W. 2007. Long-Term Management of Building Stocks. Building Research \& Information 35(4): 351-62.

Kohler, N; Steadman, P \& Hassler, U; (2009) Research on the building stock and its applications. Building Research \& Information 37(5-6): 449-454.

Larkham, P. 1996. Conservation and the City. New York: Routledge.

Lemmens, M. 2007. GIM. GIM-International. [online] [accessed 14 November 2017].

Available at: <https://www.gim-international.com/content/article/lidar-3>.

Licciardi, G. \& Amirtahmasebi, R. 2012. The Economics of Uniqueness. Urban Development Series. Washington, D.C.: The World Bank. [online]

[accessed 14 November 2017]. Available at:

<http://siteresources.worldbank.org/EXTSDNET/Resources/Economics_of_Uni queness.pdf>.

Liu, B. (2013) NYC's PLUTO data, Visualized - Finding the oldest buildings in the 5 boroughs. [online] [accessed 14 November 2017]. Available at: <http://bdon.org/building-age-nyc/\#12/40.7392/-73.9651>.

Liu, G., Xu, K., Zhang, X. \& and Zhang, G. 2014. Factors Influencing the Service Lifespan of Buildings: An Improved Hedonic Model. Habitat International 43(Supplement C): 274-82.

Mason, B. 2013. Brilliant Maps Reveal Age of the World's Buildings | WIRED. WIRED. [online] [accessed 14 November 2017]. Available at: <https://www.wired.com/2013/10/building-ages-map-gallery/>.

Masucci, A.P., Stanilov, K. \& and Batty, M. 2013. Limited Urban Growth: London's Street Network Dynamics since the 18th Century. PLOS ONE 8(8): e69469. 
Masucci, A.P., Stanilov, K. \& and Batty, M. 2014. Exploring the Evolution of London's Street Network in the Information Space: A Dual Approach. Physical Review E 89(1): 012805.

Meinel, G., Hecht, R. \& Herold, H. 2009. Analyzing Building Stock Using Topographic Maps and GIS. Building Research \& Information 37(5-6): 468-82.

Miatto, A., Schandl, H. \& Tanikawa, H. 2017. How Important Are Realistic Building Lifespan Assumptions for Material Stock and Demolition Waste Accounts? Resources, Conservation and Recycling 122(Supplement C): 143-54.

Murcio, R., Masucci, A.P., Arcaute, E. \& and Batty, M. 2015. Multifractal to Monofractal Evolution of the London Street Network. Physical Review E 92(6): 062130.

Neidhart, H. \& Sester, M. 2004. Identifying Building Types and Building Clusters Using 3D-Laser Scanning and GIS Data. In ??.

NLS. 2017. Explore Georeferenced Maps - Map Images. National Library of Scotland.

[online] [accessed 14 November 2017]. Available at:

$<$ http://maps.nls.uk/geo/explore/\#zoom=17\&lat=54.1538\&lon=-

$2.4699 \&$ layers $=171 \& b=1>$.

NTHP. 2014. Older Smaller Better - Preservation Leadership Forum - A Program of the National Trust for Historic Preservation. [online] [accessed 14 November 2017]. Available at: <http://forum.savingplaces.org/act/pgl/older-smaller-better>.

NYC. 2017. PLUTO and MapPLUTO. [online] [accessed 14 November 2017].

Available at: <https://www1.nyc.gov/site/planning/data-maps/open-data/dwnpluto-mappluto.page>.

NYPL. 2017a. Building Inspector - Kill Time. Make History. [online] [accessed 14 November 2017]. Available at: <https://buildinginspector.nypl.org/>.

NYPL. 2017b. Maps by Decade - NYC Space/Time Directory. [online] [accessed 14 November 2017]. Available at: < http://spacetime.nypl.org/maps-by-decade/\#/> .

O’Connor, J. 2004. Survey on Actual Service Lives for North American Buildings.

Woodframe Housing Durability and Disaster Issues. October 2004 [conference presentation] Las Vegas. [online] [accessed 14 November 2017]. Available at: 〈http://cwc.ca/wp-content/uploads/2013/12/DurabilityService_Life_E.pdf〉.

OKFN. 2017. Property Assessment — Datasets - US City Open Data Census. [online] [accessed 14 November 2017]. Available at: <http://uscity.census.okfn.org/dataset/assessment>. 
Open data.stack exchange. 2015. Usa - Ownership of US County Property

Tax/Assessment Data? - Open Data Stack Exchange. [online] [accessed 14 November 2017]. Available at:

<https://opendata.stackexchange.com/questions/574/ownership-of-us-countyproperty-tax-assessment-data>.

Palmer, J. 2017. Labratrevenge - Justin Palmer. [online] [Accessed ]. Available at: <http://labratrevenge.com/pdx/\#12/45.4800/-122.6706>.

Peccarelli, B. 2017. Big Data Comes to the Tax Assessor's Office. Thomson Reuters. [online] [accessed 14 November 2017]. Available at: $<$ https://blogs.thomsonreuters.com/answerson/big-data-tax-assessors-office/>.

Power, A. \& Katz, B. 2016. Lessons from a Crowded Continent: International Handbook of City Recovery. Bristol: Policy Press.

Ravetz, J. 2008. State of the Stock-What Do We Know about Existing Buildings and Their Future Prospects? Energy Policy, Foresight Sustainable Energy Management and the Built Environment Project, 36 (12): 4462-70.

Reimerink, L. 2016. How the Netherlands Turns Transparency with Property Values into Trust with Taxpayers. [online] [accessed 14 November 2017]. Available at: <http://citiscope.org/story/2016/how-netherlands-turns-transparency-propertyvalues-trust-taxpayers>.

Roumpani, F. 2016. Twitter post. 17 March 2016 [online] [accessed 14 November 2017]. Available at: <https://twitter.com/en_topia/status/710512041019252736>.

Salvati, A., Coch, H. \& Morganti, M. 2017. Effects of Urban Compactness on the Building Energy Performance in Mediterranean Climate. Energy Procedia, CISBAT 2017 International ConferenceFuture Buildings \& Districts - Energy Efficiency from Nano to Urban Scale, 122(Supplement C): 499-504. [online] [accessed 14 November 2017]. Available at: <https://doi.org/10.1016/j.egypro.2017.07.303>.

Sartori, I., Holck Sandberg, N. \& Brattebø, H. 2016. Dynamic Building Stock Modelling: General Algorithm and Exemplification for Norway. Energy and Buildings, Towards an energy efficient European housing stock: monitoring, mapping and modelling retrofitting processes, 132 (Supplement C): 13-25. Schiller, G. 2007. Urban Infrastructure: Challenges for Resource Efficiency in the Building Stock. Building Research \& Information 35(4): 399-411. 
Spaan, B. 2015. All Buildings in the Netherlands, Shaded by Year of Construction. [online] [accessed 14 November 2017]. Available at: $<$ http://code.waag.org/buildings/>.

Stanilov, K. 2012. Planning the Growth of a Metropolis: Factors Influencing Development Patterns in West London, 1875-2005. Journal of Planning History 12(1): 28-48. [online] [accessed 14 November 2017]. Available at: <https://doi.org/10.1177/1538513212454813>.

Stanilov, K. \& Batty, M. 2011. Exploring the Historical Determinants of Urban Growth Patterns through Cellular Automata. Transactions in GIS 15(3): 253-71.

Steadman, P., Liddiard, R. \& Shipworth, D. 2014. UK $\quad$ Energy Lab: Feasibility Study Final ReportAnnex G-Non-Domestic settings. UCL Energy Lab. [online] [accessed 14 November 2017]. Available at: <https://www.ucl.ac.uk/steapp/docs/lukes-reports/annex-g>.

Symonds, P., Taylor, J., Mavrogianni, A., Davies, M., Shrubsole, C., Hamilton, I. \& Chalabi, Z. 2017. Overheating in English Dwellings: Comparing Modelled and Monitored Large-Scale Datasets. Building Research \& Information 45(1-2): 195-208.

Tanikawa, H., Fishman, T., Okuoka, K. \& Sugimoto, K. 2015. The Weight of Society Over Time and Space: A Comprehensive Account of the Construction Material Stock of Japan, 1945-2010. Journal of Industrial Ecology 19(5): 778-91.

Tanikawa, H. \& Hashimoto, S. 2009. Urban Stock over Time: Spatial Material Stock Analysis Using 4d-GIS. Building Research \& Information 37(5-6): 483-502. Thomsen, A \& Flier, K. 2011. Understanding Obsolescence: A Conceptual Model for Buildings. Building Research \& Information 39(4): 352-62.

Tooke, T. R., Coops, N.C. \& Webster, J. 2013. Predicting Building Ages from LiDAR Data with Random Forests for Building Energy Modeling. Energy and Buildings 68: 603-10.

UNESCO. 2017. Historic Urban Landscape Approach Explained. UNESCO World Heritage Centre. [online] [accessed 14 November 2017]. Available at: $<$ http://whc.unesco.org/en/news/1026/>.

United Nations. 2013. Property Tax Regimes in Europe. The Global Urban Economic Dialogue Series. UN-HABITAT.

United Nations. 2014. World's Population Increasingly Urban with More than Half Living in Urban Areas | UN DESA | United Nations Department of Economic 
and Social Affairs. [online] [accessed 14 November 2017]. Available at: <world-urbanization-prospects-2014.html>.

VOA. 2017. Valuation Office Agency - Data.Gov.Uk. [online] [accessed 14 November 2017]. Available at: <https://data.gov.uk/publisher/valuation-office-agency>.

Whitehand, J. 2007. Conzenian Urban Morphology and Urban Landscapes. In Proceedings of the Sixth International Space Syntax Symposium. Istanbul. [online] [accessed 14 November 2017]. Available at: <www.spacesyntaxistanbul.itu.edu.tr/papers/invitedpapers/Jeremy_whitehand.p df $>$. 